\title{
Challenging obesity, diabetes, and addiction: the potential of lorcaserin extended release
}

This article was published in the following Dove Press journal: Diabetes, Metabolic Syndrome and Obesity:Targets and Therapy

\author{
Ryan T Hurt ${ }^{1-4}$ \\ Manpreet S Mundi ${ }^{3}$ \\ Jon O Ebbert ${ }^{5}$
}

'Division of General Internal Medicine, Mayo Clinic, Rochester, MN, USA; ${ }^{2}$ Division of Gastroenterology and Hepatology, Mayo Clinic, Rochester, MN, USA; ${ }^{3}$ Division of Endocrinology, Diabetes, Metabolism and Nutrition, Mayo Clinic, Rochester, MN, USA; ${ }^{4}$ Division of Gastroenterology, Hepatology and Nutrition, University of Louisville, Louisville, KY, USA; ${ }^{5}$ Division of Primary Care Internal Medicine, Mayo Clinic, Rochester, MN, USA
Correspondence: Ryan T Hurt Division of General Internal Medicine, Mayo Clinic, 200 First Street SW, Rochester, MN 55905, USA

Tel + I 507284 446I

Email hurt.ryan@mayo.edu

\begin{abstract}
Obesity is a global epidemic that is a leading cause of preventable death. In addition to lifestyle modification, there are numerous obesity treatments for clinicians to consider, including medications. Lorcaserin immediate release/extended release (IR/XR) is a US Food and Drug Administration approved medication for overweight and obese patients to be used with lifestyle modifications. Lorcaserin is thought to reduce weight by targeting the serotonin $\left(5 \mathrm{HT}_{2 \mathrm{c}}\right)$ system to induce satiety. Lorcaserin IR has been shown to be effective in reducing weight in overweight (body mass index [BMI] $>27 \mathrm{~kg} / \mathrm{m}^{2}$ ) and obese $\left(\mathrm{BMI}>30 \mathrm{~kg} / \mathrm{m}^{2}\right.$ ) participants in three large Phase III trials. In addition, lorcaserin has been shown to reduce post-cessation weight gain and improved smoking cessation in a randomized placebo-controlled trial. A recent meta-analysis suggested in overweight diabetic patients lorcaserin may be added to first-line oral hypoglycemic medications to enhance reduction in glycated hemoglobin. Lorcaserin is generally well tolerated with the most common side effect being headache, which is typically self-limiting. Lorcaserin $\mathrm{XR}$ (once daily) was recently approved and has been shown to be bioequivalent to lorcaserin IR (twice daily) in a pivotal study. Lorcaserin XRs, main advantage over the IR formulation is the once daily dosing regimen, which likely would lead to improved adherence and thus improved clinical effectiveness. The present review will evaluate the lorcaserin clinical studies (obesity, diabetes, and addiction), XR bioequivalence studies, pharmacogenomics of the serotonin $\left(5 \mathrm{HT}_{2 \mathrm{c}}\right)$ system, and adherence data in once daily versus twice daily medications.
\end{abstract}

Keywords: lorcaserin, Belviq ${ }^{\circ}$, obese, pharmacotherapy

\section{Introduction}

Nearly two-thirds of the United States' (US) adult population is either overweight (body mass index $[\mathrm{BMI}]>25 \mathrm{~kg} / \mathrm{m}^{2}$ ) or obese $\left(\mathrm{BMI}>30 \mathrm{~kg} / \mathrm{m}^{2}\right) .{ }^{1}$ Obesity is not just isolated to the US and is a global epidemic with estimates of 2 billion people being overweight or obese using the same BMI cutoffs. ${ }^{2}$ Obesity is associated with a wide range of comorbidities including type 2 diabetes mellitus (DM2), hypertension, cardiovascular disease, and many types of cancer. ${ }^{3-5}$ Individuals who are obese class II $\left(B M I=35.0-39.9 \mathrm{~kg} / \mathrm{m}^{2}\right)$ and above also have increased risk of all-cause mortality. ${ }^{6}$ These associated conditions and the increased all-cause mortality combined with both direct and indirect medical costs (i.e., preventative, diagnostic, and treatment) have a significant economic impact of hundreds of billions of dollars in the US alone..$^{7-9}$

The cause of the obesity epidemic is complex but likely a combination of genetic predisposition (>25 known genes with strong obesity association) and obesogenic environmental factors (i.e., decreased physical activity and increased availability of low 
cost caloric dense food). ${ }^{4,10}$ The wide range of comorbities, complex neuroendocrine physiology, and variability of adipose deposition (i.e., central versus peripheral) all contribute to the heterogeneity of obesity. ${ }^{4,10}$ Due to this heterogeneity and its numerous phenotypes, a single treatment strategy for all obese patients is not likely to be successful. Similar to other heterogeneous disease states, such as cancer, treatments have variable responses to different phenotypes..$^{10,11}$ Each patient and treatment plan would potentially benefit from an individualized medicine approach depending on the phenotypes involved and thus require the availability of a wide range of treatment options.

Fortunately, with increased need, there have now emerged a number of treatment options available for obesity, including numerous caloric options, medications, as well as both endoscopic procedures and bariatric surgery., ${ }^{5,12}$ Regardless of the number of options available, implementation of healthy lifestyle changes focused on caloric restriction, and enhanced physical activities are the foundation of any treatment plan. Unfortunately, despite the development of intense lifestyle modification programs through landmark trials, such as the Diabetes Prevention Program and the LOOK Ahead trial, most are not able to achieve long-term sustained weight loss with this approach alone..$^{14,15}$ Therapies such as bariatric surgery are an option for those with BMI $>35 \mathrm{~kg} / \mathrm{m}^{2}$ with medical comorbidities or those with BMI $>40 \mathrm{~kg} / \mathrm{m}^{2}$, with the two most common procedures being the Roux-en-Y gastric bypass and the sleeve gastrectomy. ${ }^{13}$ The US Food and Drug Administration (FDA) has also recently approved a number of endoscopically placed devices such as the intragastric balloons and aspiration devices. ${ }^{13}$ However, many find endoscopic approaches and bariatric surgery too invasive of an option and opt for other approaches.

Pharmacotherapy has been one of the oldest therapeutic options for the treatment of obesity and the last 6 years has seen a number of new medications being approved by the US FDA (Table 1). ${ }^{12}$ Two of these options are combinations of generic medications with different mechanisms of action (phentermine/topiramate and bupropion/naltrexone). The two other medications have novel mechanisms of action with liraglutide being a glucagon like peptide (GLP-1) agonist, which was first approved for diabetes, and lorcaserin targeting the serotonin (5HT) $2 \mathrm{C}$ receptors. ${ }^{16}$ Previously, fenfluramine was an approved pharmacotherapy that was a nonselective 5HT agonist that resulted in increased cardiac valvulopathy. This led to its removal from market, and the drive to develop more selective serotonin medications eventually led to the discovery and development of lorcaserin. Lorcaserin recently had an extended release (lorcaserin XR) once-a-day dosing approved. The current paper will appraise the clinical trials involving lorcaserin immediate release (IR) and lorcaserin $\mathrm{XR}$ in the areas of obesity, diabetes, and addiction. We will describe the pharmacokinetics (PK) of the XR formulation and discuss the pharmacogenomics of lorcaserin and how this could be potentially applied to the evolving world of individualized medicine.

\section{Lorcaserin IR/XR}

\section{Indication, dosage, and abuse potential}

Lorcaserin IR was approved by the US FDA for use in obese adults in June of 2012 followed by Lorcaserin XR in July 2016 under the trade name Belviq ${ }^{\circ} /$ Belviq $\mathrm{XR}^{\odot}$ (Eisai Inc., Tokyo, Japan). Lorcaserin is approved in a number of other countries including Canada, Mexico, Australia, and Brazil. The indication for use is as an adjunct to improved lifestyle (caloric restriction and increased activity) in those with obesity class I $\left(\mathrm{BMI}>30 \mathrm{~kg} / \mathrm{m}^{2}\right)$ or a BMI $\geq 27 \mathrm{~kg} / \mathrm{m}^{2}$ with at least one weight-related medical comorbidity. Unfortunately, weight- or obesity-related comorbidities are not clearly defined and thus greater than 60 medical conditions could possibly qualify. ${ }^{4}$ The recommended dose for lorcaserin IR is $10 \mathrm{mg}$ taken orally twice a day and $20 \mathrm{mg}$ once-a-day for lorcaserin XR taken either with or without food. As with other XR medications, lorcaserin XR should not be cut, crushed, or chewed. ${ }^{17}$

One of the more controversial decisions by the US Drug Enforcement Agency (DEA) was listing lorcaserin in Schedule IV of the Controlled Substances Act. ${ }^{18}$ The justification seemed to focus on lorcaserin's potential for abuse as measured by increases in subjective measures, including hallucinations and euphoria, being comparable to the schedule IV drug zolpidem $(13 \%-16 \%) .{ }^{18}$ There is data that counters this position including a placebo-controlled crossover study of 35 recreational polydrug users that were randomized to lorcaserin (20, 40, and $60 \mathrm{mg}$ ), zolpidem (15 and $30 \mathrm{mg}$ ), ketamine (100 $\mathrm{mg}$ ), or placebo single doses evaluated hallucinations and euphoria. The authors concluded that compared to ketamine (schedule III) and zolpidem (schedule IV), high doses of lorcaserin caused a significant level of aversion. Other studies with duration of 4 weeks to 2 years in obese individuals with doses up to $40 \mathrm{mg}$ have demonstrated low $(<1 \%)$ levels of hallucinations and euphoria. ${ }^{17}$ Other medications such as selective serotonin reuptake inhibitors (SSRIs) have similar properties when taken in supratherpuetic doses but do not have schedule IV designation. ${ }^{19}$ The DEA received a number of comments about the scheduling with most individuals 
Table I Approved pharmacologic agents for the treatment of obesity

\begin{tabular}{|c|c|c|c|}
\hline Drug & Mechanism & Contraindications & Common adverse effects \\
\hline Phentermine & Sympathomimetic & $\begin{array}{l}\text { Pregnancy, breastfeeding, glaucoma, } \\
\text { hyperthyroidism, use of MAOI within I } 4 \text { days, } \\
\text { history of cardiovascular disease }\end{array}$ & $\begin{array}{l}\text { Insomnia, tremor, headache, risk of } \\
\text { dependency, palpitations, elevated blood } \\
\text { pressure }\end{array}$ \\
\hline Orlistat & $\begin{array}{l}\text { Pancreatic lipase } \\
\text { inhibitor }\end{array}$ & $\begin{array}{l}\text { Pregnancy, cholestasis, chronic malabsorption } \\
\text { syndromes }\end{array}$ & $\begin{array}{l}\text { Abdominal pain, bloating, diarrhea, acute } \\
\text { pancreatitis, renal failure }\end{array}$ \\
\hline Lorcaserin IR/XR & $\begin{array}{l}\text { Selective serotonin } 2 \mathrm{C} \\
\text { receptor agonist }\end{array}$ & Pregnancy & $\begin{array}{l}\text { Headache, back pain, nasopharyngitis, nausea, } \\
\text { dizziness }\end{array}$ \\
\hline $\begin{array}{l}\text { Phentermine- } \\
\text { topiramate ER }\end{array}$ & $\begin{array}{l}\text { Sympathomimetic and } \\
\text { anticonvulsant }\end{array}$ & $\begin{array}{l}\text { Pregnancy, breastfeeding, glaucoma, } \\
\text { hyperthyroidism, use of MAOI within } 14 \text { days, } \\
\text { history of cardiovascular disease }\end{array}$ & $\begin{array}{l}\text { Dizziness, dry mouth, constipation, } \\
\text { depression, insomnia, tremor, headache, risk } \\
\text { of dependency, palpitations, elevated blood } \\
\text { pressure }\end{array}$ \\
\hline $\begin{array}{l}\text { Bupropion/ } \\
\text { naltrexone SR }\end{array}$ & $\begin{array}{l}\text { Dopamine and NE } \\
\text { reuptake inhibitor/opioid } \\
\text { receptor antagonist }\end{array}$ & $\begin{array}{l}\text { Pregnancy, uncontrolled HTN, history of } \\
\text { seizures, bulimia or anorexia, use of MAOI } \\
\text { within } 14 \text { days }\end{array}$ & $\begin{array}{l}\text { Nausea, constipation, headache, vomiting, } \\
\text { insomnia, dizziness, dry mouth, diarrhea }\end{array}$ \\
\hline Liraglutide & GLP-I agonist & $\begin{array}{l}\text { Pregnancy, family history of medullary thyroid } \\
\text { carcinoma or multiple endocrine neoplasia } \\
\text { syndrome type } 2\end{array}$ & $\begin{array}{l}\text { Nausea, diarrhea, vomiting, headache, } \\
\text { dyspepsia, dizziness, abdominal pain }\end{array}$ \\
\hline
\end{tabular}

Abbreviations: ER, extended release; GLP-I, glucagon like peptide; HTN, hypertension; IR, immediate release; NE, Norepinephrine; MAOI, monoamine oxidase inhibitor; $S R$, sustained release; $X R$, extended release.

supporting the decision based on the indication of a weightloss medication leading to a high demand and the schedule IV would provide a control on over-prescription. ${ }^{18}$ Based on the available data, abuse potential is low, and as with any lowrisk drug, clinicians should still monitor for signs of abuse.

\section{Pharmacodynamics}

Lorcaserin belongs to a class of medications that is thought to selectively act on the $5 \mathrm{HT}_{2}$ system to promote weight loss through a satiety mechanism by activation of pro-opiomelancortin neurons. ${ }^{20}$ Previously approved medications in this class (fenfluramine and dexfenfluramine) were removed from the market due to association with valvular heart disease likely due to agonist activity of the $5 \mathrm{HT}_{2 \mathrm{~B}}$ receptors, which have increased expression in cardiac tissue..$^{21,22}$ Unlike these earlier 5HT medications, lorcaserin is a highly selective agonist for the $5 \mathrm{HT}_{2 \mathrm{C}}$ receptors that are primarily located in the brain, including the hypothalamus, thalamus, striatum, prefrontal cortex, and amygdala. ${ }^{20,23}$ Lorcaserin has a 60 -fold greater potency to act at the $5 \mathrm{HT}_{2 \mathrm{C}}$ receptor versus the $5 \mathrm{HT}_{2 \mathrm{~B}}$ receptor, making the risk of cardiac involvement lower than that of previous drugs. ${ }^{18,24,25}$ In over 5,000 patients from large Phase III trials who received echocardiography monitoring for valvular heart disease, the rate of new valvulopathy was the same for lorcaserin $(2.37 \%)$ as placebo $(2.04 \%)$ at 52 weeks (risk difference $0.33 \%$ : $95 \% \mathrm{CI},-0.46$ to 1.13 ). ${ }^{26}$ Because lorcaserin is more likely to act at the $5 \mathrm{HT}_{2 \mathrm{C}}$ versus $5 \mathrm{HT}_{2 \mathrm{~B}}$ receptor, it would take supertheraputic doses to elicit $5 \mathrm{HT}_{2 \mathrm{~B}}$ effects, which may include hallucinations..$^{17,18,24,25}$
A recent functional MRI study was performed in 48 obese participants who were randomized to 4 weeks of lorcaserin IR or placebo to determine the effects of the drug on the brain when presented with food cues while being scanned. ${ }^{27} \mathrm{~A}$ total of 36 participants completed the 4-week protocol (19 placebo and 17 lorcaserin) with headache occurring in three lorcaserin and one placebo. The regions of the brain that demonstrated significant different activity in the lorcaserin group when viewing the food cues included the insula, parietal cortex, visual cortices, cuneus, hippocampus, and amygdala. ${ }^{27}$ There were no differences in the activation of the hypothalamus as seen in rodent studies, which the authors hypothesized could have been due to artifacts or the small sample size. ${ }^{27}$ Based on the patterns of activation in the insula and amygdala, they did hypothesize that lorcaserin could be targeted to emotional eating phenotype of obesity. ${ }^{27}$ In addition, these areas of the brain activation show similar patterns to the brains of individuals during drug intoxication or during cravings. ${ }^{28}$ These brain areas involved include those specifically involved with the learning/memory circuits of addiction (amygdala and hippocampus).$^{28}$ Similar to food cues, a person, place, or drug cue can bring back memories of the drug or food and lead to an intense desire for consuming it. ${ }^{28}$

\section{Pharmacokinetics}

Lorcaserin is an oral medication that is absorbed by the gastrointestinal tract and is available in two forms: lorcaserin IR (10 mg taken twice a day) and lorcaserin XR (20 mg taken once a day). Lorcaserin is extensively metabolized 
by liver cytochrome P450 (CYP) and flavin-containing monooxygenase (FMO) enzymes with the majority of the metabolites being excreted in the urine $(>90 \%) .{ }^{29}$ There are a number of primary metabolites for lorcaserin (lorcaserin sulfamate, $N$-carbamoyl glucuronide lorcaserin, $N$-hydroxylorcaserin, 7-hydroxylorcaserin, 5-hydroxylorcaserin, and 1-hydroxylorcaserin) that are biologically active but do not activate the $5 \mathrm{HT}_{2 \mathrm{C}}$ receptors. ${ }^{29}$ Unlike other commonly prescribed medications affecting the serotonin system (i.e., SSRIs and serotonin and norepinephrine reuptake inhibitors [SNRIs]) whose metabolism is primarily achieved by a few liver CYPs, lorcaserin is metabolized by multiple CYPs and FMO (CYP1A1, CYP1A2, CYP2A6, CYP2B6, CYP2C19, CYP2D6, CYP3A4, and FMO1). Being metabolized by a few enzymes can lead to increased effectiveness in individuals with polymorphisms but may also increase drug-drug interactions by concomitant medications. A recent study hypothesized that these interactions were not as likely to be problematic with lorcaserin due to the multiple metabolic enzymatic pathways. ${ }^{29}$ The package instructions still calls for caution with CYP2D6-mediated metabolism as a study of 21 extensive metabolizers found that 4 days of lorcaserin and dextromethorphan raised the $\mathrm{C}_{\max }$ of the former by $76 \%{ }^{17}$

Two recent randomized crossover clinical trials evaluated the PK of lorcaserin IR versus lorcaserin XR. ${ }^{30}$ The overall goal of these industry-sponsored studies was to compare the bioequivalence of lorcaserin IR versus XR (based on area under the curve $[\mathrm{AUC}]$ ) and that the plasma drug concentrations $\left(C_{\max }\right)$ were not higher for XR. The first study randomized 36 healthy participants (age $18-45$ years, BMI $18-45 \mathrm{~kg} / \mathrm{m}^{2}$ ) to one of two treatments under fasting conditions: (A) 1 day of lorcaserin IR $10 \mathrm{mg}$ taken twice a day followed by a 3-day washout and then 5 days of lorcaserin IR $10 \mathrm{mg}$ taken twice a day and (B) 1 day of lorcaserin XR $20 \mathrm{mg}$ once daily followed by a 3-day washout period and then 5 days of lorcaserin XR $20 \mathrm{mg}$ once daily. ${ }^{30}$ After completion of the first treatment course, a 5-day washout period occurred and then those initially assigned to treatment A or B were crossed over to the other group. ${ }^{30} \mathrm{~A}$ total of 34 participants finished the protocol. After a single dose of lorcaserin, the median time to peak dose $\left(t_{\max }\right)$ was 3 hours (1.5-4 hours) for IR and 12 hours (6-16 hours) for XR. The mean $C_{\max }$ was lower for the XR (38.8 $\mathrm{ng} / \mathrm{mL})$ compared to IR $(52.3 \mathrm{ng} / \mathrm{mL})$ but the AUC was not different (IR, $1240 \mathrm{~h} \cdot \mathrm{ng} / \mathrm{mL} ; \mathrm{XR}, 1217 \mathrm{~h} \cdot \mathrm{ng} / \mathrm{mL}$ ). After five doses (steady state), the time to plasma-steady state was the same and $t_{\max }$ was 1.5 hours (1-3 hours) for IR and 10 hours (6-12 hours) for XR. ${ }^{31}$ The authors concluded that the AUC (IR $1328 \mathrm{~h} \cdot \mathrm{ng} / \mathrm{mL} ; \mathrm{XR} 1235 \mathrm{~h} \cdot \mathrm{ng} / \mathrm{mL}$ ) and mean $C_{\text {max }}$ (IR, 80.1 $\mathrm{ng} / \mathrm{mL} ; \mathrm{XR}, 73.9 \mathrm{ng} / \mathrm{mL}$ ) were within statistical boundaries when using geometric mean ratio analysis $(90 \% \mathrm{CI})$ and could be considered bioequivalent. ${ }^{30}$

The second study, which was also reported in the same manuscript, used a different group of 36 participants who all finished the protocol. The primary aim of the second study was to evaluate the effect of fasting/fed state on the PK of lorcaserin XR. The first group consisted of 1 day of lorcaserin XR $20 \mathrm{mg}$ followed by a 3-day washout and then 5 days of lorcaserin XR $20 \mathrm{mg}$ taken daily. The lorcaserin was delivered in the morning after $\mathrm{a} \geq 10$ hours fasting period. The second group received the same schedule but the drug was delivered during a fed state, which was 20 minutes after a standardized high-fat meal of $800-1000 \mathrm{kcal}(50 \%$ of the total calories from fat). ${ }^{30}$ As with the first study, participants were crossed over after a 5-day washout period to the other treatment group. Lorcaserin XR reached steady state after 5 days under both fasting and fed states. Fasted steady-state AUC (1216 h.ng/mL) and $C_{\max }(69.5 \mathrm{ng} / \mathrm{mL})$ were comparable to the fed-state AUC $(1318 \mathrm{~h} \cdot \mathrm{ng} / \mathrm{mL})$ and $C_{\max }(78.7 \mathrm{ng} / \mathrm{mL})$. The authors concluded that taking lorcaserin XR with food does not likely have an effect on absorption under steady-state conditions.

\section{Adverse effects and contraindications}

The two lorcaserin XR PK studies noted 150 treatmentemergent adverse events (TEAEs) considered mild to moderate and reported by 50 participants. No serious TEAEs were reported during either of the studies. Of the 150 TEAEs, there were a total of 72 reported in $\geq 5 \%$ of participants. The number of participants $(n=36)$ reporting a TEAE was similar between lorcaserin IR $(50 \% ; n=18)$ and XR $(n=17)$ groups in the first study. Although the sample size was small, there were twice as many cases of headaches with lorcaserin IR (16) compared to XR (7)..$^{30}$ Other central nervous system symptoms such as nausea, presyncope, and dizziness did occur in $\geq 5 \%$ of subjects but did not appear to be different in IR versus XR groups. Gastrointestinal symptoms such as abdominal pain, constipation, and nausea were less frequent in XR $(n=3)$ versus IR $(n=6)$ but the small sample size makes drawing conclusions difficult. ${ }^{30}$

There are over 6000 patients in the lorcaserin IR placebocontrolled database evaluating adverse reactions (Table 2). In trials greater than 1 year, there were more participants who stopped lorcaserin (8.6\%) versus placebo (6.7\%). Of those that discontinued the medications, headache, depression, and dizziness were the most common reasons. The TEAEs reported in greater than $2 \%$ of the nondiabetic participants and more commonly in lorcaserin than placebo included nausea (lorcaserin 
Table 2 The adverse events from clinical trials at least I year in duration involving lorcaserin that occurred in $2 \%$ of nondiabetic participants more often than placebo adapted from the package insert

\begin{tabular}{|c|c|c|}
\hline \multirow[t]{2}{*}{ Adverse reaction } & \multicolumn{2}{|l|}{ Number of patients (\%) } \\
\hline & Lorcaserin $(\mathbf{N}=3195)$ & Placebo $(\mathbf{N}=3185)$ \\
\hline \multicolumn{3}{|l|}{ Gastrointestinal disorders } \\
\hline Nausea & $264(8.3)$ & $170(5.3)$ \\
\hline Diarrhea & $207(6.5)$ & $179(5.6)$ \\
\hline Constipation & $186(5.8)$ & $125(3.9)$ \\
\hline Dry mouth & $169(5.3)$ & $74(2.3)$ \\
\hline Vomiting & $122(3.8)$ & $83(2.6)$ \\
\hline \multicolumn{3}{|c|}{ General disorders and administration site conditions } \\
\hline Fatigue & $229(7.2)$ & $114(3.6)$ \\
\hline \multicolumn{3}{|l|}{ Infections and infestations } \\
\hline Upper respiratory tract infection & $439(13.7)$ & $391(12.3)$ \\
\hline Nasopharyngitis & $4 \mid 4(13.0)$ & $381(12.0)$ \\
\hline Urinary tract infection & $207(6.5)$ & I7| (5.4) \\
\hline \multicolumn{3}{|c|}{ Musculoskeletal and connective tissue disorders } \\
\hline Back pain & $201(6.3)$ & $178(5.6)$ \\
\hline Musculoskeletal pain & $65(2.0)$ & $43(1.4)$ \\
\hline \multicolumn{3}{|l|}{ Nervous system disorders } \\
\hline Headache & $537(16.8)$ & $321(10.1)$ \\
\hline Dizziness & $270(8.5)$ & $122(3.8)$ \\
\hline \multicolumn{3}{|c|}{ Respiratory, thoracic, and mediastinal disorders } \\
\hline Cough & $136(4.3)$ & $109(3.4)$ \\
\hline Oropharyngeal pain & III (3.5) & $80(2.5)$ \\
\hline Sinus congestion & $93(2.9)$ & $78(2.4)$ \\
\hline \multicolumn{3}{|l|}{ Skin and subcutaneous tissue disorders } \\
\hline Rash & $67(2.1)$ & $58(1.8)$ \\
\hline
\end{tabular}

$8.3 \%$; placebo 5.3\%), constipation (lorcaserin 5.8\%; placebo $3.9 \%$ ), dry mouth (lorcaserin $5.3 \%$; placebo $2.3 \%$ ), headaches (lorcaserin 16.8\%; placebo 10.1\%), and dizziness (lorcaserin $8.5 \%$; placebo 3.8\%). In diabetic (lorcaserin $n=256$; placebo $\mathrm{n}=252$ ) participants, the number of TEAEs was similar to the nondiabetics with the exception of hypoglycemia being more common in lorcaserin (29.3\%) than placebo (21.0\%).

In addition to the common adverse reactions, there are a number of contraindications and warnings that clinicians should be aware of. Because of the bioequivalence of lorcaserin, these warnings should be applied to the XR version. Serotonin syndrome is a serious condition involving increased serotonergic neurological activity that can lead to increased morbidity and potentially death. ${ }^{31}$ The incidence of serotonin syndrome is difficult to determine due to numerous factors, including poor recognition by health care providers. ${ }^{32}$ It has been increasingly recognized in the past 30 years as a result of the wide use of SSRIs and SNRIs for mood disorders. Signs and symptoms can be mild/moderate, such as akathisia and tremor, and these can progress to life threatening ones, such as sustained clonus, hyperthermia, and altered mental status. ${ }^{31}$ A retrospective analysis of the large Phase III lorcaserin IR studies evaluated those participants who took protocol-allowed or prescribed drugs and did not find increased adverse event (AE) risk including serotonin syndrome. ${ }^{33}$ The incidence of serotonin syndrome associated with lorcaserin use is unknown, and clinicians should avoid or use caution in both IR and XR with patients on SSRIs, SNRIs, or any other class of drug that could increase serotonin such as monoamine oxidase inhibitors.

There are a number of other potential side effects from the use of 5- $\mathrm{HT}_{2 \mathrm{C}}$ agonists that clinicians should be aware of. Although not recognized in the Phase III trials, priapism is a potential serious side effect of lorcaserin. ${ }^{17}$ In addition, lorcaserin may raise serum levels of prolactin at slightly higher rates than placebo, so those with signs and symptoms of gynecomastia or galactorrhea should be evaluated. Although there were no signs of teratogenicity in animal data, lorcaserin has been considered contraindicated in pregnancy due to weight-loss potential in women and low body weight of the fetus. ${ }^{17}$ There is no human data on the effects of locaserin IR/XR on human milk, so it is not recommended in breastfeeding mothers. ${ }^{17}$ 


\section{Pharmacogenomics}

The main target of lorcaserin is the $5-\mathrm{HT}_{2 \mathrm{C}}$ receptor, which is encoded by the gene HTR2C. The HTR2C gene has been mapped to human chromosome $\mathrm{X}$ band q24. ${ }^{34}$ Knockout mice for $5-\mathrm{HT}_{2 \mathrm{C}}$ developed hyperphagia and eventually obesity compared to controls, which led to the development of lorcaserin..$^{35}$ There are a number of polymorphisms in the upstream region of the $H T R 2 C$ gene that have been identified and potentially associated with obesity. Two specific SNPs (rs3813929 and rs518147) in the HTR2C gene promoter region have been associated with lower rates of obesity. ${ }^{36}$ The first is rs3813929, a substitution (C to T) in the -759 of the promoter region. The second is rs518147, a substitution ( $\mathrm{G}$ to $\mathrm{C}$ ) in the -697 promoter region. ${ }^{36,37}$ Both of these variants are thought to be partially protective for developing obesity by increasing transcription levels of the $5-\mathrm{HT}_{2 \mathrm{C}}$ receptor leading to improved control of satiety. ${ }^{36}$ There are a number of studies that have found that the HTR2C polymorphisms rs3813929 and rs518147 have been associated with reduced antipsychotic medication weight gain. ${ }^{37-41}$ Antipsychotic medications such as olanzapine antagonize the $5-\mathrm{HT}_{2 \mathrm{C}}$ receptor potentially leading to reduced control of satiety. In the largest of these studies $(\mathrm{n}=107)$, no participant who had $\mathrm{rs} 3813929(0 / 28)$ developed a $\geq 10 \%$ increase in BMI compared to $36.2 \%(21 / 58)$ of the wild type (-759 C) after 6 weeks of olanzapine. ${ }^{37}$ Furthermore, only $5.9 \%(3 / 51)$ of participants with rs 518147 developed a $\geq 10 \%$ increase in BMI compared to $32.1 \%(18 / 56)$ of the wild type (-697 G) after 6 weeks of olanzapine. The $-759 \mathrm{~T}$ allele frequency from this study was $24.5 \%$ (13/53) in men and $27.8 \%(15 / 54)$ in women. Of the women (who are homozygotic) with the $-759 \mathrm{~T}$ allele, only one participant (1/54) had two copies. The $-697 \mathrm{C}$ allele frequency was $41.5 \%$ (22/53) in men and $53.7 \%(29 / 54)$ in women. Of those women with the $-697 \mathrm{C}$ allele, $18.5 \%(10 / 54)$ had two copies. Although there has not been a pharmacogenomics study involving lorcaserin, this could lead to a better targeted treatment population that could optimally respond to the drug with minimal side effects.

\section{Lorcaserin clinical studies Overweight and obesity}

Lorcaserin IR was approved by the US FDA in 2012 for overweight and obese patients on the basis of three large Phase III randomized controlled trials. ${ }^{42-44}$ Two of these studies evaluated overweight and obese participants who did not have DM2. The first of these studies known as the Behavioral Modification and Lorcaserin for Obesity and Overweight Management (BLOOM) trial was conducted in 98 study sites throughout the US. ${ }^{44} \mathrm{~A}$ total of 3182 overweight or obese participants were randomized to receive lorcaserin IR $10 \mathrm{mg}(\mathrm{n}=$ $1595)$ or placebo $(\mathrm{n}=1553)$ twice a day with all individuals receiving lifestyle counseling sessions. Participants that were still enrolled at 52 weeks were eligible to remain in the trial for another 52 weeks. ${ }^{44}$ Participants that were in the placebo group continued to receive placebo and those in lorcaserin initially were randomized to receive lorcaserin or placebo in a 2:1 ratio. ${ }^{44}$ The two co-primary aims at 52 weeks were percentage of participants losing $\geq 5 \%$ and $\geq 10 \%$ of baseline body weight. ${ }^{44}$ The primary end point for 104 weeks was the ratio of participants who had $\geq 5 \%$ weight loss at 52 weeks who maintained it at 104 weeks. $^{44}$

There were no significant differences in the baseline characteristics of the participants in the two groups. The completion rate was higher in lorcaserin $(55 \%)$ versus placebo $(45 \%)$ at 52 weeks. Of those who continued the study after 52 weeks, the completion rate at 104 weeks was $73 \%$ with discontinuation rates being similar for all groups. Headaches were more common in lorcaserin (18\%) versus placebo (11\%) at 52 weeks, and adverse events (AEs) causing withdrawal from the study was slightly higher in lorcaserin $(7.1 \%$ versus $6.7 \%)$. The main finding of the study was at 52 weeks, $47 \%$ of participants assigned to lorcaserin had $\geq 5 \%$ baseline weight loss compared to $20.3 \%$ assigned placebo $(P<0.001)$. In addition, locaserin $(22.6 \%)$ had significantly more participants lose $\geq 10 \%$ of baseline body weight than placebo $(P<0.001)$. For those participants randomized at 52 weeks, a higher percentage maintained the $\geq 5 \%$ weight loss in lorcaserin (68\%) versus placebo (50\%) at 104 weeks.

The second Phase III Behavioral Modification and Lorcaserin Second Study for Obesity Management (BLOSSOM) study had similar inclusion criteria to the BLOOM trial. ${ }^{42}$ One of the main differences in the BLOSSOM trial design was the addition of a lorcaserin IR $10 \mathrm{mg}$ once per day treatment arm. Participants $(n=4008)$ were randomized to lorcaserin IR $10 \mathrm{mg}$ twice daily, lorcaserin IR $10 \mathrm{mg}$ daily, or placebo in a 2:1:2 ratio for 52 weeks. ${ }^{42}$ Similar to the BLOOM trial, the two co-primary aims were proportion (percentage) of participants losing $\geq 5 \%$ and $\geq 10 \%$ of baseline body weight. ${ }^{42,44}$ Baseline demographics were similar in the three treatment arms. A total of $55 \%$ of participants $(n=2224)$ completed the trial at 52 weeks. Participants randomized to lorcaserin IR twice daily (47.2\%) and once daily (40.2\%) both were significantly more likely to achieve $\geq 5 \%$ weight loss than placebo $(25 \%)$ at 52 weeks $(P<0.0001)$. Additionally, $\geq 10 \%$ weight loss was achieved more often in lorcaserin IR $(22.6 \%$ twice daily; $17.4 \%$ once daily) than placebo $(9.7 \%)$. The 
number of participants who withdrew due to AEs and the frequency of the most common $\mathrm{AE}$ (headache) were similar to the BLOOM trial. One of the major conclusions that can be drawn for clinical practice is that once daily dosing was more effective than placebo and may be an option for patients experiencing mild AEs to the standard twice daily dosing.

\section{Type 2 Diabetes}

There is a high correlation between being overweight or obese and developing DM2 in adults. Greater than $85 \%$ of DM2 patients in the US are either overweight or obese. ${ }^{45}$ Just a 5\% weight loss in DM2 patients can improve metabolic outcomes, including glycated hemoglobin $\left(\operatorname{HgBA} 1_{c}\right)$. The BLOOM-DM study examined lorcaserin IR for weight loss in participants with a BMI $>27 \mathrm{mg} / \mathrm{kg}^{2}$ who also had DM2. In a similar design to the BLOSSOM trial, a total of 604 participants were randomized to either placebo, lorcaserin IR $10 \mathrm{mg}$ once daily, or lorcaserin IR $10 \mathrm{mg}$ twice daily for 52 weeks in a 1:1:1 ratio. The primary end points were proportion (percentage) of participants losing $\geq 5 \%$ and $\geq 10 \%$ of baseline body weight and overall change in weight at 52 weeks. Important DM2-associated secondary aims included changes from baseline $\operatorname{HgBA}_{\mathrm{c}}$, fasting plasma glucose, and fasting insulin. As with BLOSSOM, more patients lost $\geq 5 \%$ body weight with lorcaserin twice daily $(37.5 \%$; $P<$ $0.001)$ or lorcaserin daily $(44.7 \% ; P<0.001)$ compared to placebo (16.1\%). Common AEs were headache, back pain, nasopharyngitis, and nausea. And like BLOOM and BLOSSOM trials, serial echocardiograms did not demonstrate increased incidence of valvular heart disease compared to placebo. ${ }^{26}$ In addition to the significant weight loss, there was improvement in glycemic control in these overweight or obese DM2 participants. The decrease in $\mathrm{HgBA}_{c}$ was significantly different for both doses of lorcaserin IR compared to placebo (lorcaserin twice daily $0.9 \pm 0.06$, lorcaserin once daily $1.0 \pm 0.09$, placebo $0.4 \pm 0.06 ; P<0.001$ ).

One of the main clinical questions that arise from the BLOOM-DM study is how lorcaserin IR/XR can be best utilized in DM2 patients. A recent meta-analysis was performed to compare lorcaserin IR to other non-insulin DM2 medications for weight loss and glycemic control. ${ }^{46}$ The 41 trials included in the analysis were published between 1990 and 2014 and had to report changes in weight, $\mathrm{HgBA}_{c}$ and/or rates of hypoglycemia. ${ }^{46}$ Not surprisingly, lorcaserin IR had significantly higher amounts of weight loss when compared to sulfonylureas and thiazolidinediones and no difference between $\alpha$-glucoside inhibitors and GLP-1 agonists. Lorcaserin IR was found to be non-inferior compared to all classes of non-insulin DM2 medications evaluated (GLP-1 agonist, acarbose, sulfonylurea, thiazolidnedione, DPP-4 inhibitor, glinide, and SGLT-2 inhibitor) in the percentage $\mathrm{HgBA}_{\mathrm{c}}$ reduction and percentage achieving $\mathrm{HgBA} 1_{\mathrm{c}}<7 \%$. Compared to placebo only, the glinides and sulfonylureas had significantly higher risk of hypoglycemia. The authors concluded that in those DM2 patients with a BMI $>27 \mathrm{mg} / \mathrm{kg}^{2}$, lorcaserin could be considered when optimal glycemic control is not achieved with a single oral agent (metformin) and lifestyle modifications. ${ }^{46}$

\section{Addiction}

There are a number of animal studies that have suggested that lorcaserin could be beneficial in the treatment of alcohol, cocaine, and nicotine addiction. ${ }^{47-51}$ In humans, lorcaserin IR has been used in a large $(\mathrm{n}=603)$ multicentered double-blind randomized controlled trial for smoking cessation. ${ }^{52}$ Participants in the study included those who expressed motivation to quit smoking, were smoking at least 10 cigarettes/day for the past year with no period of abstinence greater than 3 months, $18-65$ years of age, and a BMI of $18.5-38.0 \mathrm{~kg} / \mathrm{m}^{2} .52$ Participants were enrolled at 30 sites with a range of 12 to 26 participants per site. A total of 603 smokers were randomized to one of three arms: lorcaserin IR $10 \mathrm{mg}$ per day $(\mathrm{n}=$ $202)$, lorcaserin IR $10 \mathrm{mg}$ twice a day $(\mathrm{n}=201)$, or placebo ( $\mathrm{n}=200$ ) for 12 weeks. ${ }^{52}$ All participants had brief weekly cessation counseling lasting $\sim 10$ minutes. Target quit date was set for day 15 . The stated primary end point was exhaled carbon monoxide $(\mathrm{CO})$ confirmed continuous abstinence rate (CAR) for weeks 9-12 in the modified intent-to-treat population. Participants had to verbally report no tobacco use, which was confirmed by weekly exhaled $\mathrm{CO}$ values of $\leq 10$ ppm. $^{52}$

The 12-week CARs were 5.6\%, 8.7\%, and $15.3 \%$ in the placebo, daily, and twice a day lorcaserin IR, respectively. The odds ratio (OR) for the twice a day lorcaserin versus placebo was $3.02(95 \% \mathrm{CI}, 1.47,6.22, P=0.003)$. This OR is comparable to a pivotal Phase III trial for varenicline $(3.85 ; 95 \% \mathrm{CI}$, $2.69-5.50 ; P<0.001)$ for the lorcaserin twice a day dosing. ${ }^{53}$ The 7-day point prevalence of abstinence was $11.8 \%, 13.9 \%$, and $20.4 \%$ for the placebo, daily, and twice a day dosing at 12 weeks, respectively. The number of cigarettes smoked per day was significantly reduced within all three groups $(P \leq 0.0001)$ from baseline through 12 weeks. At 12 weeks, reductions from baseline were 10.3, 10.8, and 11.6 cigarettes/day for placebo, daily, and twice a day dosing, respectively. AEs were $55 \%, 55 \%$, and $62 \%$ for placebo, daily, and twice daily lorcaserin IR, respectively. The AEs were for the most part mild or 
moderate in severity with discontinuations being 3.0\%, 3.0\%, and $2.5 \%$ in the placebo, daily, and twice daily lorcaserin IR dosing, respectively. The most common AEs reported more frequently in lorcaserin IR versus placebo were headache, nausea, fatigue, dry mouth, dizziness, abnormal dreams, and constipation. No AE for lorcaserin exceeded placebo by more than $3.5 \%$. There were eight serious AEs that were not treatment related as determined by the investigators. One of the main limitations of the study was that participants were not followed up beyond the 12-week treatment phase, which is typically standard in smoking cessation trials. Despite the positive trial, there is currently no FDA-approved indication for lorcaserin IR/XR.

Post-cessation weight gain (PCWG) can be a barrier to achieving or maintaining smoking abstinence and weight concerns. In large population-based study, $52 \%$ of the women and $32 \%$ of men with a previous attempt to quit smoking reported that weight gain was one of the primary reasons for relapse back to smoking. ${ }^{54}$ In a meta-analysis of 62 studies in untreated quitters, PCWG was $2.85 \mathrm{~kg}$ at 3 months $(95 \%$ CI, 2.42-3.28), $4.23 \mathrm{~kg}$ at 6 months (95\% CI, 3.69-4.77), and $4.67 \mathrm{~kg}$ at 12 months (95\% CI, 3.96-5.38). ${ }^{55}$ Heavier and more dependent smokers may gain more weight making overweight and obese smokers a potential target population for lorcaserin IR/XR to prevent or attenuate PCWG. ${ }^{56}$

In the lorcaserin smoking cessation trial, a secondary end point was PCWG. Participants in the lorcaserin IR twice a day group $(n=194)$ had a significant reduction in weight when compared to baseline. Change from baseline at week 12 was $-0.01,-0.35$, and $-0.98 \mathrm{~kg}$ in the placebo, lorcaserin daily, and lorcaserin twice daily dosing. When responders (defined as 4 weeks of continuous abstinence from week 9-12) were compared to nonresponders, there were significant differences in PCWG. ${ }^{52}$ There was no PCWG with responders $(n=30)$ in the lorcaserin twice daily group, and there was actually a loss of weight from baseline. Other pharmacotherapies for smoking cessation such as nicotine replacement and varenicline have demonstrated minimal effect on PCWG. ${ }^{57}$ Lorcaserin IR has been used in a small clinical trial in combination with varenicline in overweight and obese smokers with no above-mentioned AEs observed, what would otherwise be expected for the individual drugs. ${ }^{58}$ Although there is no indication for smoking cessation at this time, clinicians could use lorcaserin IR/XR on label in overweight and obese smokers for weight loss that could lead to prevention or attenuation of PCWG, which is a major barrier to smoking cessation attempts.

\section{Potential benefit of lorcaserin XR versus IR}

There is limited clinical data on lorcaserin XR when compared to lorcaserin IR. US FDA approval was based on the pivotal bioequivalence studies referenced earlier. ${ }^{30}$ Based on these studies, the FDA assumed that the clinical efficacy of the lorcaserin IR would be equivalent to lorcaserin XR. Because the two formulations are likely bioequivalent and would not improve clinical outcomes, why should clinicians consider lorcaserin XR? The main advantage of lorcaserin XR is the once-a-day dosing schedule delivering the bioequivalent amount of drug that lorcaserin IR twice daily does. Medication adherence is typically defined as the extent to which a patient takes the prescription according to interval, dose, and dosing regimen. ${ }^{59}$ Adherence has been measured in clinical trials including the lorcaserin studies using various methods including pill counts at study visits, patient self-reported values, and pharmacological levels of drug in the serum. These older methods can be inaccurate compared to the bottle caps that have microprocessors, medication event monitoring systems (MEMS), that record the frequency that each cap is opened..$^{60}$ These MEMS reduce the chance of an observer effect in which patients modify behavior because they are being observed and likely mimic real-world adherence.

A systematic review evaluated the effect of daily medication adherence in chronic disease according to dosing frequency using these MEMS. ${ }^{59}$ The authors included 20 studies based on the patient populations having pharmacologically treated chronic disease for at least 6 weeks. The dosing frequency of included studies had to be between 1 and 4 days. ${ }^{59}$ For those studies comparing once-a-day dosing versus three times a day dosing, there was $22 \%-41 \%$ more adherent days in daily dosing. ${ }^{59}$ When comparing daily versus twice daily dosing, there was $2 \%-44 \%$ more adherent days in daily dosing. Based on these findings it is reasonable to assume that lorcaserin XR would lead to greater adherence than lorcaserin IR. What is not clear is whether this would equate to improved clinical efficacy in the real-world setting mimicking the findings from the Phase III trials, which likely had observer effect on the adherence of the participants (i.e., pill counts). ${ }^{61}$

\section{Conclusion}

Lorcaserin IR has been shown in three Phase III studies to be effective in weight loss in overweight and obese individuals which eventually led to US FDA approval in 2012. This was followed by approval of lorcaserin XR in 
2016 with studies demonstrating bioequivalence between it and lorcaserin IR. Lorcaserin XR has the advantage of once-a-day dosing which likely will increase compliance and thus efficacy. Individualized approach using pharmacogenomic data involving polymorphisms of the HTR2C gene may lead to even better results and help determine which patients would not respond. In addition to the label indications for overweight $\left(\mathrm{BMI}>27 \mathrm{~kg} / \mathrm{m}^{2}\right.$ plus one obesity comorbidity) and obese (BMI $>30 \mathrm{~kg} / \mathrm{m}^{2}$ ), lorcaserin has possible benefits in other comorbidities as well. A large multicentered randomized control trial demonstrated those treated with lorcaserin IR had higher rates of smoking cessation and less PCWG than placebo. Clinicians could use lorcaserin as an adjunctive therapy in overweight and obese patients, and it may prevent PCWG and help with smoking cessation. In addition, lorcaserin IR/XR could be added to overweight/obese DM2 patients to help with weight loss but also likely improve glycemic control. Finally, lorcaserin XR formulation would likely lead to improved adherence in real-world settings.

\section{Disclosure}

The authors report no conflicts of interest in this work.

\section{References}

1. Flegal KM, Kruszon-Moran D, Carroll MD, Fryar CD, Ogden CL. Trends in obesity among adults in the United States, 2005 to 2014. J Am Med Assoc. 2016;315(21):2284-2291.

2. Ng M, Fleming T, Robinson M, et al. Global, regional, and national prevalence of overweight and obesity in children and adults during 1980-2013: a systematic analysis for the Global Burden of Disease Study 2013. Lancet. 2014;384(9945):766-781.

3. Calle EE, Rodriguez C, Walker-Thurmond K, Thun MJ. Overweight, obesity, and mortality from cancer in a prospectively studied cohort of U.S. adults. $N$ Engl J Med. 2003;348(17):1625-1638.

4. Hurt RT, Frazier TH, McClave SA, Kaplan LM. Obesity epidemic: overview, pathophysiology, and the intensive care unit conundrum. J Parenter Enteral Nutr. 2011;35(5 Suppl):4S-13S.

5. Hurt RT, Kulisek C, Buchanan LA, McClave SA. The obesity epidemic: challenges, health initiatives, and implications for gastroenterologists. Gastroenterol Hepatol (N Y). 2010;6(12):780-792.

6. Flegal KM, Kit BK, Orpana H, Graubard BI. Association of all-cause mortality with overweight and obesity using standard body mass index categories: a systematic review and meta-analysis. $\mathrm{J} \mathrm{Am} \mathrm{Med} \mathrm{Assoc.}$ 2013;309(1):71-82.

7. Finkelstein EA, Trogdon JG, Cohen JW, Dietz W. Annual medical spending attributable to obesity: payer-and service-specific estimates. Health Aff (Millwood). 2009;28(5):w822-w831.

8. Trogdon JG, Finkelstein EA, Hylands T, Dellea PS, Kamal-Bahl SJ. Indirect costs of obesity: a review of the current literature. Obes Rev. 2008;9(5):489-500.

9. Allison DB, Zannolli R, Narayan KM. The direct health care costs of obesity in the United States. Am J Public Health. 1999;89(8):1194-1199.

10. Shah M, Hurt RT, Mundi MS. Phenotypes of obesity: how it impacts management. Curr Gastroenterol Rep. 2017;19(11):55.

11. Burrell RA, McGranahan N, Bartek J, Swanton C. The causes and consequences of genetic heterogeneity in cancer evolution. Nature. 2013;501(7467):338-345.
12. Hurt RT, Edakkanambeth Varayil J, Ebbert JO. New pharmacological treatments for the management of obesity. Curr Gastroenterol Rep. 2014;16(6):394.

13. Hurt RT, Frazier TH, Mundi MS. Novel nonsurgical endoscopic approaches for the treatment of obesity. Nutr Clin Pract. 2017;32(4): 493-501.

14. Wing RR, Bolin P, Brancati FL, et al. Cardiovascular effects of intensive lifestyle intervention in type 2 diabetes. $N$ Engl J Med. 2013;369(2): 145-154.

15. Knowler WC, Fowler SE, Hamman RF, et al. 10-year follow-up of diabetes incidence and weight loss in the Diabetes Prevention Program Outcomes Study. Lancet. 2009;374(9702):1677-1686.

16. Patel DK, Stanford FC. Safety and tolerability of new-generation antiobesity medications: a narrative review. Postgrad Med. 2018;130(2): $1-10$.

17. Belviq ${ }^{\circledR}$ (lorcaserin) extended release tablets [ prescribing information] Tokyo: Eisai, Inc.; 2017.

18. Drug Enforcement Administration. Schedules of controlled substances: placement of lorcaserin into Schedule IV. Federal Register, The Daily Journal of the United States Government. 2013;78-89.

19. Evans EA, Sullivan MA. Abuse and misuse of antidepressants. Subst Abuse Rehabil. 2014;5:107-120.

20. Voigt JP, Fink H. Serotonin controlling feeding and satiety. Behav Brain Res. 2015;277:14-31.

21. Roth BL. Drugs and valvular heart disease. NEngl J Med. 2007;356(1): 6-9.

22. Connolly HM, Crary JL, McGoon MD, et al. Valvular heart disease associated with fenfluramine-phentermine. NEngl J Med. 1997;337(9): 581-588.

23. Thomsen WJ, Grottick AJ, Menzaghi F, et al. Lorcaserin, a novel selective human 5-hydroxytryptamine2C agonist: in vitro and in vivo pharmacological characterization. J Pharmacol Exp Ther. 2008;325(2): 577-587.

24. Smith BM, Smith JM, Tsai JH, et al. Discovery and structure-activity relationship of (1R)-8-chloro-2,3,4,5-tetrahydro-1-methyl-1H-3-benzazepine (Lorcaserin), a selective serotonin 5-HT2C receptor agonist for the treatment of obesity. J Med Chem. 2008;51(2):305-313.

25. Smith BM, Smith JM, Tsai JH, et al. Discovery and SAR of new benzazepines as potent and selective 5-HT(2C) receptor agonists for the treatment of obesity. Bioorg Med Chem Lett. 2005;15(5):1467-1470.

26. Weissman NJ, Sanchez M, Koch GG, Smith SR, Shanahan WR, Anderson $\mathrm{CM}$. Echocardiographic assessment of cardiac valvular regurgitation with lorcaserin from analysis of 3 phase 3 clinical trials. Circ Cardiovasc Imaging. 2013;6(4):560-567.

27. Farr OM, Upadhyay J, Gavrieli A, et al. Lorcaserin administration decreases activation of brain centers in response to food cues and these emotion- and salience-related changes correlate with weight loss effects: a 4-week-long randomized, placebo-controlled, double-blind clinical trial. Diabetes. 2016;65(10):2943-2953.

28. Volkow ND, Fowler JS, Wang GJ. The addicted human brain: insights from imaging studies. J Clin Invest. 2003;111(10):1444-1451.

29. Usmani KA, Chen WG, Sadeque AJ. Identification of human cytochrome P450 and flavin-containing monooxygenase enzymes involved in the metabolism of lorcaserin, a novel selective human 5-hydroxytryptamine 2C agonist. Drug Metab Dispos. 2012;40(4):761-771.

30. Christopher R, Morgan M, Ferry J, et al. Single- and multiple-dose pharmacokinetics of a lorcaserin extended-release tablet. Clin Ther. 2016;38(10):2227-2238;e2224.

31. Boyer EW, Shannon M. The serotonin syndrome. $N$ Engl J Med. 2005;352(11):1112-1120.

32. Mackay FJ, Dunn NR, Mann RD. Antidepressants and the serotonin syndrome in general practice. Br J Gen Pract. 1999;49(448):871-874.

33. Nguyen CT, Zhou S, Shanahan W, Fain R. Lorcaserin in obese and overweight patients taking prohibited serotonergic agents: a retrospective analysis. Clin Ther. 2016;38(6):1498-1509.

34. Milatovich A, Hsieh CL, Bonaminio G, Tecott L, Julius D, Francke U. Serotonin receptor $1 \mathrm{c}$ gene assigned to $\mathrm{X}$ chromosome in human (band q24) and mouse (bands D-F4). Hum Mol Genet. 1992;1(9):681-684. 
35. Tecott LH, Sun LM, Akana SF, et al. Eating disorder and epilepsy in mice lacking 5-HT2c serotonin receptors. Nature. 1995;374(6522): 542-546.

36. Yuan X, Yamada K, Ishiyama-Shigemoto S, Koyama W, Nonaka K. Identification of polymorphic loci in the promoter region of the serotonin 5-HT2C receptor gene and their association with obesity and type II diabetes. Diab Tologia. 2000;43(3):373-376.

37. Godlewska BR, Olajossy-Hilkesberger L, Ciwoniuk M, et al. Olanzapine-induced weight gain is associated with the $-759 \mathrm{C} / \mathrm{T}$ and $-697 \mathrm{G} / \mathrm{C}$ polymorphisms of the HTR2C gene. Pharmacogenomics $J$. 2009;9(4):234-241.

38. Ma X, Maimaitirexiati T, Zhang R, et al. HTR2C polymorphisms, olanzapine-induced weight gain and antipsychotic-induced metabolic syndrome in schizophrenia patients: a meta-analysis. Int J Psychiatry Clin Pract. 2014;18(4):229-242.

39. Malan-Muller S, Kilian S, van den Heuvel LL, et al. A systematic review of genetic variants associated with metabolic syndrome in patients with schizophrenia. Schizophr Res. 2016;170(1):1-17.

40. De Luca V, Mueller DJ, de Bartolomeis A, Kennedy JL. Association of the HTR2C gene and antipsychotic induced weight gain: a metaanalysis. Int J Neuropsychopharmacol. 2007;10(5):697-704.

41. Sicard MN, Zai CC, Tiwari AK, et al. Polymorphisms of the HTR2C gene and antipsychotic-induced weight gain: an update and metaanalysis. Pharmacogenomics. 2010;11(11):1561-1571.

42. Fidler MC, Sanchez M, Raether B, et al. A one-year randomized trial of lorcaserin for weight loss in obese and overweight adults: the BLOSSOM trial. J Clin Endocrinol Metab. 2011;96(10):3067-3077.

43. O'Neil PM, Smith SR, Weissman NJ, et al. Randomized placebocontrolled clinical trial of lorcaserin for weight loss in type 2 diabetes mellitus: the BLOOM-DM study. Obesity (Silver Spring). 2012;20(7):1426-1436

44. Smith SR, Weissman NJ, Anderson CM, et al. Multicenter, placebocontrolled trial of lorcaserin for weight management. $N$ Engl J Med. 2010;363(3):245-256.

45. Eberhardt MS, Ogden CL, Engelgau M, Cadwell B, Hedley AA, Saydah S. Prevalence of overweight and obesity among adults with diagnosed diabetes--United States, 1988-1994 and 1999-2002. Morb Mortal Wkly Rep. 2004;53(45):1066-1068.

46. Neff LM, Broder MS, Beenhouwer D, Chang E, Papoyan E, Wang ZW. Network meta-analysis of lorcaserin and oral hypoglycaemics for patients with type 2 diabetes mellitus and obesity. Clin Obes. 2017;7(6):337-346.

47. Levin ED, Johnson JE, Slade S, et al. Lorcaserin, a 5-HT2C agonist, decreases nicotine self-administration in female rats. J Pharmacol Exp Ther. 2011;338(3):890-896.
48. Zeeb FD, Higgins GA, Fletcher PJ. The serotonin 2C Receptor agonist lorcaserin attenuates intracranial self-stimulation and blocks the rewardenhancing effects of nicotine. ACS Chem Neurosci. 2015;6(7):1231-1240.

49. Gannon BM, Sulima A, Rice KC, Collins GT. Inhibition of cocaine and 3,4-Methylenedioxypyrovalerone (MDPV) self-administration by lorcaserin is mediated by 5-HT2C receptors in rats. $J$ Pharmacol Exp Ther. 2018;364(2):359-366.

50. Collins GT, Gerak LR, Javors MA, France CP. Lorcaserin reduces the discriminative stimulus and reinforcing effects of cocaine in rhesus monkeys. J Pharmacol Exp Ther. 2016;356(1):85-95.

51. Rezvani AH, Cauley MC, Levin ED. Lorcaserin, a selective 5-HT(2C) receptor agonist, decreases alcohol intake in female alcohol preferring rats. Pharmacol Biochem Behav. 2014;125:8-14.

52. Shanahan WR, Rose JE, Glicklich A, Stubbe S, Sanchez-Kam M. Lorcaserin for smoking cessation and associated weight gain: a randomized 12-week clinical trial. Nicotine Tob Res. 2017;19(8):944-951.

53. Jorenby DE, Hays JT, Rigotti NA, et al. Efficacy of varenicline, an alpha4beta2 nicotinic acetylcholine receptor partial agonist, vs placebo or sustained-release bupropion for smoking cessation: a randomized controlled trial. J Am Med Assoc. 2006;296(1):56-63.

54. Pisinger $\mathrm{C}$, Jorgensen $\mathrm{T}$. Waist circumference and weight following smoking cessation in a general population: the Inter99 study. Prev Med. 2007;44(4):290-295.

55. Aubin HJ, Farley A, Lycett D, Lahmek P, Aveyard P. Weight gain in smokers after quitting cigarettes: meta-analysis. Br Med J. 2012;345:e4439.

56. Williamson DF, Madans J, Anda RF, Kleinman JC, Giovino GA, Byers T. Smoking cessation and severity of weight gain in a national cohort. N Engl J Med. 1991;324(11):739-745.

57. Farley AC, Hajek P, Lycett D, Aveyard P. Interventions for preventing weight gain after smoking cessation. Cochrane Database Syst Rev. 2012;1:CD006219.

58. Hurt RT, Croghan IT, Schroeder DR, Hays JT, Choi DS, Ebbert JO. Combination varenicline and lorcaserin for tobacco dependence treatment and weight gain prevention in overweight and obese smokers: a pilot study. Nicotine Tob Res. 2017;19(8):994-998.

59. Saini SD, Schoenfeld P, Kaulback K, Dubinsky MC. Effect of medication dosing frequency on adherence in chronic diseases. Am J Manag Care. 2009;15(6):e22-e33.

60. Claxton AJ, Cramer J, Pierce C. A systematic review of the associations between dose regimens and medication compliance. Clin Ther. 2001;23(8):1296-1310.

61. Hanson KA, Payne KA. Targeted literature review of medication event monitoring systems to evaluate adherence in observational real-world studies. Value Health. 2014;17(7):A645.

Diabetes, Metabolic Syndrome and Obesity: Targets and Therapy

Dovepress

\section{Publish your work in this journal}

Diabetes, Metabolic Syndrome and Obesity: Targets and Therapy is an international, peer-reviewed open-access journal committed to the rapid publication of the latest laboratory and clinical findings in the fields of diabetes, metabolic syndrome and obesity research. Original research, review, case reports, hypothesis formation, expert opinion and commentaries are all considered for publication. The manuscript management system is completely online and includes a very quick and fair peer-review system, which is all easy to use. Visit http://www.dovepress.com/testimonials.php to read real quotes from published authors. 